\title{
Hypophysiotropic and Neuromodulatory Regulation of Adrenocorticotropin in the Human Fetal Pituitary Gland
}

\author{
Zeev Blumenfeld and Robert B. Jaffe \\ Reproductive Endocrinology Center, Department of Obstetrics, Gynecology and Reproductive Sciences, University of California, San \\ Francisco, California 94143
}

\begin{abstract}
Synthetic human corticotropin-releasing factor (hCRF) stimulated ACTH secretion by human fetal pituitaries in superfusion and dispersed human fetal pituitary cells cultured on an extracellular matrix in static incubation from 14 to 23 wk gestational age. The action of hCRF in vitro was potentiated by arginine vasopressin (AVP) at all ages studied. 8-Br-cAMP induced a response similar to hCRF. The AVP effect on ACTH was synergistic with both CRF and 8-Br-cAMP. hCRF-mediated secretion of ACTH was noncompetitively inhibited by 24-h pretreatment, or by 3-h concomitant treatment, with dexamethasone. Neither oxytocin, catecholamines, prostaglandins, nor indomethacin exerted significant effects on ACTH secretion, either alone or in combination with hCRF or AVP during the gestational ages studied.

These results support a physiologic role for CRF in the regulation of secretion by corticotropic cells as early as 14 wk gestation, by which time corticotropes and ability to secrete ACTH have been demonstrated.
\end{abstract}

\section{Introduction}

Adenohypophyseal secretion of ACTH can be elicited by intrinsic and extrinsic stimuli. Many studies have been performed concerning the physiologic, anatomic, and pharmacologic aspects of the ACTH regulatory system (1-6). These studies support the concept of a complex system subserved by multiple factors of hypothalamic, neurohypophyseal, and peripheral origins (1). The constellation of putative regulatory factors presently associated with the control network includes corticotropin-releasing factor $(\mathrm{CRF})^{1}$ (7), arginine vasopressin (AVP) (8), epinephrine (9), and, possibly, oxytocin (10). The presence of each of these factors in hypophyseal portal plasma of the rat has been reported $(1,11-$ 17), and high-affinity receptors for CRF (18), AVP (19), and

This work was presented in part at the Annual Meeting of the Society for Gynecologic Investigation, Phoenix, AZ, 1985; and at the 67th Annual Meeting of the Endocrine Society, Baltimore, MD, 1985.

Dr. Blumenfeld's present address is Department of Obstetrics and Gynecology, Rambam Medical Center, Haifa, Israel. Address correspondence to Dr. Jaffe.

Received for publication 18 November 1985.

1. Abbreviations used in this paper: AVP, arginine vasopressin; CMF, Hanks' calcium and magnesium-free buffer, CRF, corticotropin-releasing factor; ECM, extracellular matrix; M199/EBSS, medium 199/Earle's balanced salt solution; $P G s$, prostaglandins; $P_{G E}$, prostaglandin $E_{2}$.

J. Clin. Invest.

(C) The American Society for Clinical Investigation, Inc. 0021-9738/86/07/0288/07 \$1.00

Volume 78, July 1986, 288-294 epinephrine (20) have been identified in adenohypophyseal tissue. A variety of in vitro and in vivo studies suggest that the action of CRF may be modulated by glucocorticoids (21-28), catecholamines $(23,29)$, neurohypophyseal peptides $(21,23,30$ 32), prostaglandins (33), and other substances.

Therefore, we assessed the ability of human fetal pituitary cells to respond to a variety of substances which have been reported to regulate ACTH secretion in adult animals. Others have suggested that the human fetal pituitary cannot respond to CRF until after 20 wk gestation $(34,35)$. However, we have identified human fetal corticotropic cells by the 12th wk of pregnancy, using immunocytochemical techniques (36); others have demonstrated the ability of human fetal pituitaries to secrete ACTH by the end of the first trimester (37). Therefore we sought to ascertain whether the human fetal pituitary could respond to CRF and AVP before 20 wk gestation. To do this, we performed both superfusion and static incubation studies.

\section{Methods}

33 human fetuses at 14-23 wk of gestation were obtained within $2 \mathrm{~h}$ of therapeutic termination of pregnancy by evacuation after laminaria-induced dilatation.

Superfusion. In the first eight cases, the fetal pituitary was removed and placed in ice-cold medium 199/Earle's balanced salt solution (M199/ EBSS) and transported to the laboratory. Each pituitary was divided into six fragments to increase surface area, placed in a tissue chamber containing superfusion medium, and submerged in a $37^{\circ} \mathrm{C}$ water bath. The superfusion system was modified from that described by Kraicer and Chow (38). The superfusion chamber was composed of an O-ring Pyrex joint (G9235-1/11, Corning 6780, American Scientific Products, McGaw Park, IL) with an internal diameter of $5 \mathrm{~mm}$. The pituitary fragments were placed on a $0.5-\mathrm{mm}$ thick scintered glass disc filter fitted with a rubber gasket and held between the Pyrex joints by a metal clamp. The superfusion medium was M199/EBSS (prepared by the cell culture facility of the University of California, San Francisco [UCSF]) consisting of $0.1 \%$ bovine serum albumin (BSA, fraction V, $98-99 \%$ albumin; Sigma Chemical Co., St. Louis, MO), $20 \times 10^{-6} \mathrm{M}$ bacitracin, $10^{-3} \mathrm{M}$ ascorbate, $25 \mathrm{mM}$ Hepes buffer, and saturated with $95 \% \mathrm{O}_{2}$ and $5 \% \mathrm{CO}_{2}$. The medium was pumped from a $37^{\circ} \mathrm{C}$ reservoir by a peristaltic pump (Manostat Corp., New York, NY) at a rate of $0.3 \mathrm{ml} / \mathrm{min}$ through a four-way valve (SRV-4; Pharmacia Fine Chemicals, Piscataway, NJ). This system permitted instant changing of the medium inflow into the chamber with minimal pressure changes. All connecting tubing was PE 160, i.d., 0.045 in. (Clay Adams, Parsippany, NJ) and the connectors were stainless steel (Small Parts Inc., Miami, FL). The effluent from the tissue chamber was collected on ice in sequential 10-min fractions, using a fraction collector (model 328; Isco, Inc., Lincoln, NE). The effluent was divided into three aliquots and stored at $-70^{\circ} \mathrm{C}$ until assay.

Synthetic human CRF was purchased from Peninsula Laboratories (Belmont, CA), dissolved in $10^{-3} \mathrm{~N} \mathrm{HCl}$ in normal saline, and slowly injected into the superfusion system (first three superfusions). In the next five superfusions, the CRF was diluted in the superfusion medium within 5 min and equilibrated with $\mathrm{O}_{2} / \mathrm{CO}_{2}$ in a reservoir identical to the medium reservoir. It was then superfused as a 10-min square-wave through the peristaltic pump, using the four-way valve to minimize pressure changes. 
AVP (Bachem, Torrance, CA) was dissolved in normal saline ( $\mathrm{pH}$ 4.5) and then diluted in medium. $\mathrm{KCl}$ was dissolved in superfusion medium at a concentration of $60 \mathrm{mM}$ and administered as a 10-min squarewave at the end of each superfusion.

The purity of CRF and AVP was confirmed by high performance liquid chromatography. CRF was chromatographed on a C-18 column using a flow rate of $1 \mathrm{ml} / \mathrm{min}$ and a linear gradient over $40 \mathrm{~min}$ from $100 \% 0.05 \mathrm{M} \mathrm{NaH}_{2} \mathrm{PO}_{4}$ to $40 \%$ acetonitrile in the phosphate buffer. AVP was analyzed on a C-18 column using the method of O'Hare and Nice (39).

8-Br-cAMP, used in both superfusions and incubations, was obtained from Sigma Chemical Co.

Preparation of dispersed cells and static incubations. Dexamethasone, norepinephrine, isoproterenol, prostaglandin E, indomethacin, and oxytocin were obtained from Sigma Chemical Co. Dulbecco's Modified Eagle's Medium H-16; M199/EBSS; Hanks' calcium (0.9\%) magnesiumfree (CMF) buffer; fetal bovine serum; and saline with $0.1 \%$ trypsin $(0.05 \%)$ and versine $(0.02 \%)$; were supplied by the cell culture facility at UCSF. All media contained $100 \mu \mathrm{g} / \mathrm{ml}$ penicillin, $100 \mu \mathrm{g} / \mathrm{ml}$ streptomycin, $2 \mu \mathrm{M}$ glutamine, and $25 \mathrm{mM}$ Hepes buffer. Fibroblast growth factor was purified from bovine brains according to the method of Gospodarowicz et al. (40). Tissue culture dishes were purchased from Falcon Labware, Becton, Dickinson \& Co., Oxnard, CA. All cultures were maintained at $37^{\circ} \mathrm{C}$ in a $\mathrm{CH} / \mathrm{P}$ incubator (Forma Scientific, Div. of Mallinckrodt, Marietta, $\mathrm{OH}$ ) with $95 \% \mathrm{O}_{2}-5 \% \mathrm{CO}_{2}$.

Extracellular matrix (ECM). The use of an ECM derived from bovine corneal endothelial cells for maintenance of human pituitary cells in culture has been previously described $(41,42)$. The ECM produced by bovine corneal endothelium has now been used extensively for the culture of various normal and neoplastic cells (43). Recently, the use of this matrix provided a successful means for culturing human pituitary adenoma cells, which adhere poorly to plastic $(41,42)$. The use of ECM can also circumvent the need for various attachment factors in serum (4345). Culture of bovine corneal endothelial cells and the production of ECM were performed according to the method of Gospodarowicz et al. (46). In brief, for matrix production, stock cultures of corneal endothelium were split with saline with $0.1 \%$ trypsin and versine, and the corneal endothelial cells $\left(3 \times 10^{4} / \mathrm{ml}\right)$ were plated in 24-well plates with Dulbecco's modified Eagle's medium containing 15\% fetal bovine serum, 5\% (wt/ vol) dextran T-40, and antibiotics as described above. Fibroblast growth factor $(100 \mathrm{ng} / \mathrm{ml})$ was added three times during the first week. After reaching confluence (within 6-7 d), the cultures were incubated for 710 additional days, during which time the matrix was deposited. The cells were removed with a rapid wash in $20 \mathrm{mM}$ ammonium hydroxide.

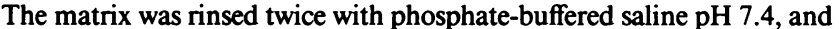
the plates containing phosphate-buffered saline and antibiotics were stored at $4^{\circ} \mathrm{C}$.

Pituitary dispersion. Each of the 25 human fetal pituitaries used for static incubations (14-23 wk gestation) was removed within $2 \mathrm{~h}$ of pregnancy termination and placed in Hanks' CMF buffer at room temperature. Four term rhesus fetal pituitaries, utilized for comparison, were obtained after hysterotomy. The tissue was minced in fresh Hanks' CMF, and the fragments were transferred to a $15-\mathrm{ml}$ conical tube and centrifuged at $300 \mathrm{~g}$ for $1 \mathrm{~min}$. The buffer was aspirated and $5 \mathrm{ml}$ of Hanks' CMF containing $0.5 \%$ collagenase and a total of $50 \mu \mathrm{g}$ DNAase were added. This was incubated at $37^{\circ} \mathrm{C}$ for $1 \mathrm{~h}$ in a Dubnoff metabolic shaking incubator (Precision Scientific 66722; American Scientific Products, McGaw Park, IL), after which an additional $50 \mu \mathrm{g}$ DNAase were added and the tissue was mechanically dispersed in $5 \mathrm{ml}$ Hanks' CMF by trituration with a $5 \mathrm{ml}$ pipette. Any remaining fibrous tissue fragments were allowed to settle and were then removed. The cell suspension was centrifuged at $150 \mathrm{~g}$ for $5 \mathrm{~min}$, and the cell pellet was resuspended in M199/ EBSS containing $10 \% \mathrm{FBS}$ and plated at a density of 7.5-10 $\times 10^{4}$ cells per ECM-coated well.

Incubation. After 3-4 d in culture, the cells, by this time firmly attached to the ECM, were washed and preincubated with serum-free medium containing $0.1 \%$ BSA. After a 90 -min preincubation period, the cells were washed again and secretagogues were added in M199/EBSS containing $0.1 \%$ BSA, penicillin/streptomycin, Hepes buffer, and glutamine; $1 \mathrm{ml}$ per well. Each treatment was performed in quadruplicate or quintuplicate wells. After a 3-h incubation with either medium (control), $10 \mathrm{nM} \mathrm{CRF}, 10$ or $100 \mathrm{nM} \mathrm{AVP}$, or a combination of these secretagogues, the medium was collected in cold polystyrene Eppendorf tubes, aliquoted, and kept at $-70^{\circ} \mathrm{C}$ until assay.

After each incubation, serum-containing medium was added to the cells, which were incubated for 24-48 h. Afterwards the cells were washed and preincubated with serum-free medium, as described above. After preincubation and after 24-48 $\mathrm{h}$ incubation, the media were collected and assayed for ACTH to verify that the baseline concentration was the same in all of the wells and that the number of ACTH-secreting cells in each well was comparable. There was no difference between the increase of ACTH secretion after exposure to CRF, AVP, or both on day 3-5 (first experiment) or in subsequent experiments with the same cells.

After the experiments performed with each fetal pituitary, the cells were detached using STV solution and counted, using a Coulter counter (Coulter Electronics Inc., Hialeah, FL).

$A C T H$ radioimmunoassay. The ACTH radioimmunoassay (47) employed rabbit anti-ACTH (1-24) serum, generously provided by Dr. S. Hane, Metabolic Research Unit, UCSF. ACTH (1-39) (Calbiochem, La Jolla, CA) was used for the standard curve. The ACTH trace supplied by Dr. Hane was iodinated using a modification of the method of Hunter and Greenwood (48).

After a 48-h incubation of samples with antiserum and trace, separation of bound from free hormone was accomplished by addition of goat anti-rabbit $\gamma$-globulin. The cross-reactivity with alpha melanocytestimulating hormone was $<0.1 \%$, and the intraassay and interassay variations were $<7.5$ and $<10 \%$, respectively. The assay sensitivity was $1 \mathrm{pg}$ $\mathrm{ACTH} /$ tube. The sample volume was 20-100 $\mu \mathrm{l} /$ tube. The final antiserum concentration was 1:75,000.

Statistical analysis. Comparisons were made using one-way analysis of variance (Newman-Keuls test) (49) for each experiment. Similar experiments were analyzed using linear regression and least squares means analysis of variance with Bonferroni correction for multiple comparisons $(50)$

\section{Results}

The addition of CRF to fetal anterior pituitary cells in culture or fragments in superfusion significantly increased ACTH secretion into the medium (Figs. 1 and 2).

Superfusion of the eight 14-23-wk-old human fetal pituitaries resulted in a significant increase in ACTH in the effluent after CRF administration at all ages studied (four less than, and four greater than, 20 wks) (Fig. $2 A$ and $B$ ). The ability of the tissue to secrete ACTH was confirmed by administration of $60 \mathrm{mM}$ $\mathrm{KCl}$ at the end of each superfusion.

AVP at concentrations of $10^{-7}$ and $10^{-8} \mathrm{M}$ also increased

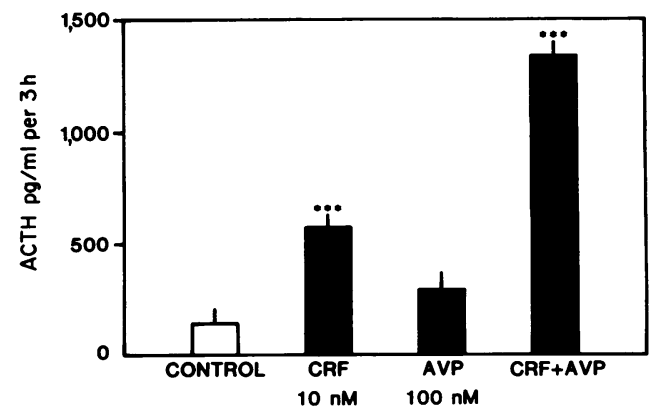

Figure 1. Mean ACTH secretion by dispersed human fetal pituitary cells from 12 fetuses after 3-h exposure to CRF (10 nM), AVP (100 $\mathrm{nM}$ ), or a combination of these secretagogues. Least square means \pm SEM. ${ }^{* * *} P<0.001$ from control. 
A

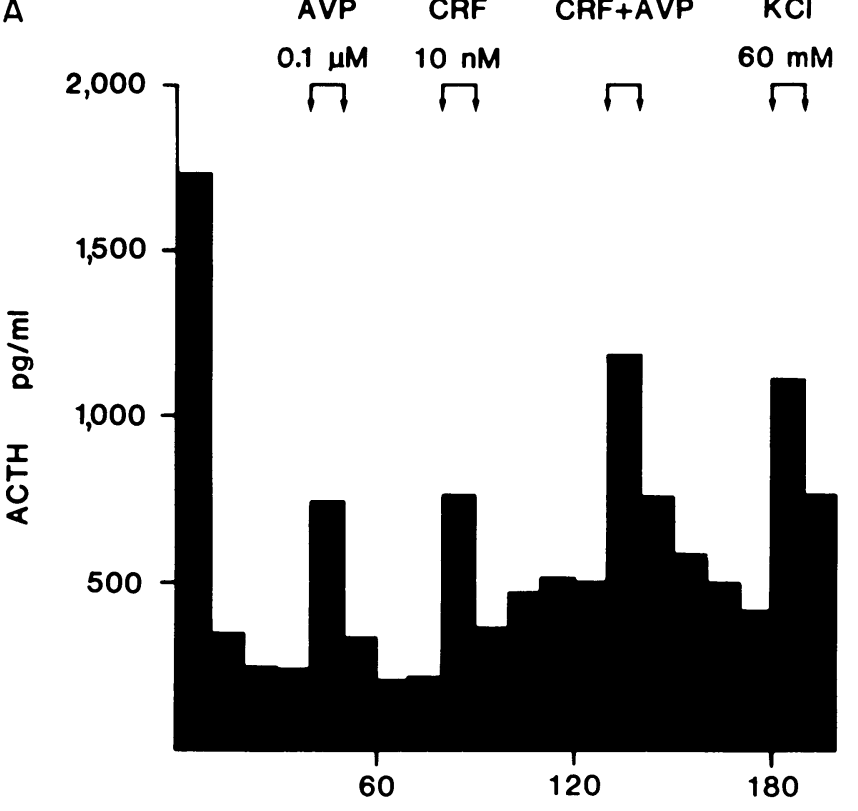

MINUTES

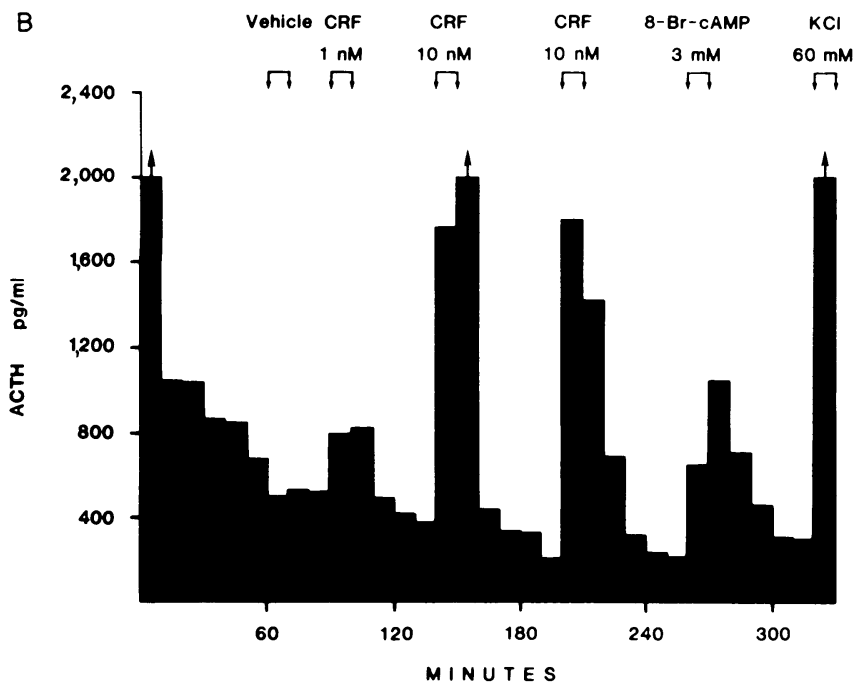

Figure 2. (A) ACTH response to CRF, AVP, a combination of these secretagogues, and $\mathrm{KCl}$ in superfusion of 14 -wk old human fetal pituitary. (B) ACTH response to CRF, 8-Br-cAMP, and $\mathrm{KCl}$ in superfusion of pituitary from an 18-wk-old human fetus.

ACTH secretion by human fetal pituitary cells, but was less potent than CRF. However, the combination of CRF and $10^{-7}$ or $10^{-8} \mathrm{M}$ AVP was synergistic and induced significantly higher ACTH secretion than that induced by either secretagogue alone (Fig. 1). The 50\% effective concentration of CRF for ACTH secretion was $0.5-1 \mathrm{nM}$ in five different experiments at fetal ages ranging from 17 to $23 \mathrm{wk}$. A representative example is shown in Fig. 3. The intrinsic activity (secretory response induced at maximally effective concentrations) of CRF was similar to that of the cAMP derivative, 8-Br-cAMP. Stimulation with $3 \mathrm{mM}$ 8-Br-cAMP in static incubations of dispersed cells (Fig. 4) or in superfusion (Fig. 2) brought about a significant increase in ACTH secretion. However, 8-Br-cAMP was an effective secretagogue for ACTH secretion only in concentrations higher than $10^{-3} \mathrm{M}$

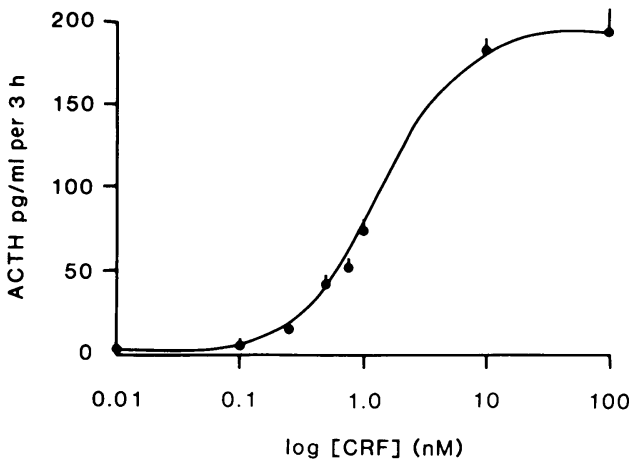

Figure 3. ACTH response to various concentrations of CRF in static incubation of dispersed human fetal pituitary cells from a 22-wk-old fetus. Mean \pm SD.

(Fig. 4). The combination of $3 \mathrm{mM}$ 8-Br-cAMP with AVP brought about a synergistic effect on ACTH secretion (Fig. 4). No such effect was detected when dispersed pituitary cells were exposed to a combination of CRF and 8-Br-cAMP.

No correlation was found between gestational age and the extent of increase in ACTH secretion by the human fetal pituitary cells (between 15 and $23 \mathrm{wk}$ ) after exposure to CRF alone or $\mathrm{CRF}+\mathrm{AVP}$. Further, in experiments with fetal pituitary cells from four term rhesus monkeys treated similarly, there was no significant difference between the increase in $\mathrm{ACTH}$ in response to $\mathrm{CRF}$ alone or CRF + AVP and that observed in the human fetal pituitary cells (data not shown).

Oxytocin did not elicit any significant change in ACTH secretion at concentrations ranging from 0.2 to $20 \mathrm{nM}$ (range of physiologic concentration in systemic and portal circulation in baseline and stress conditions) (1). Neither did the combination of oxytocin and CRF or AVP elicit any significant change in ACTH secretion from that achieved by CRF or AVP alone.

Dexamethasone inhibition of ACTH secretion. Pretreatment of the pituitary cells for $24 \mathrm{~h}$ with dexamethasone $(20 \mathrm{nM})$ sig-

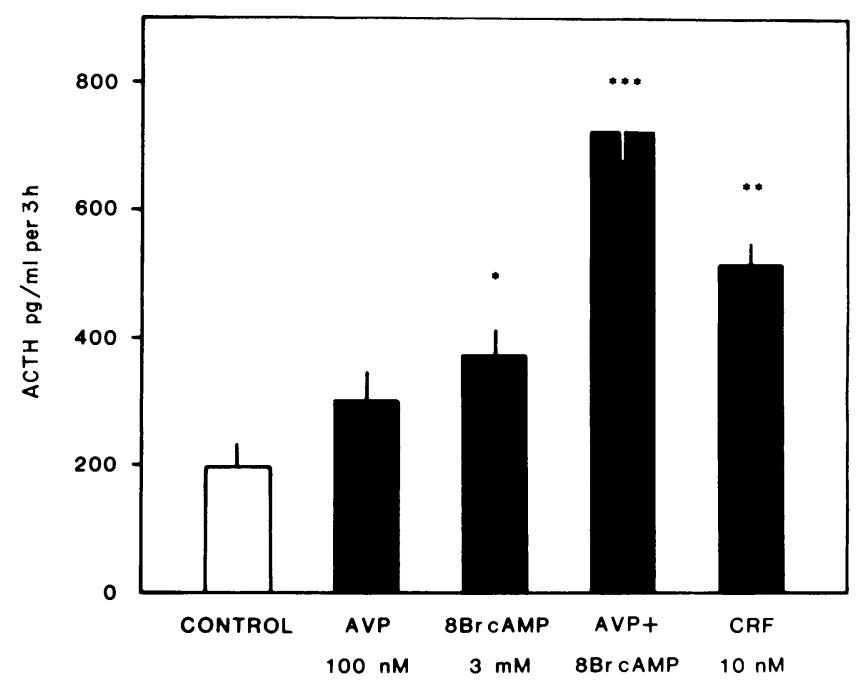

Figure 4. Mean ACTH secretion by dispersed human fetal pituitary after 3-h exposure to AVP, CRF, and 8-Br-cAMP administered singly or in combination $(n=5)$. Least square means \pm SEM. ${ }^{* * *} P<0.001$, ${ }^{* *} P<0.01,{ }^{*} P<0.05$ from control. 
nificantly reduced the amount of ACTH secreted by the cells exposed to medium alone. Subsequent 3-h exposure of the cells to $\mathrm{CRF}(10 \mathrm{nM})$ or $8-\mathrm{Br}-\mathrm{cAMP}(3 \mathrm{mM})$ elicited significantly less ACTH secretion in the dexamethasone-pretreated wells than the wells which were not pretreated with dexamethasone but were exposed to CRF or 8-Br-cAMP $(n=5)$ (Fig. 5). ACTH secretion in the control wells exposed to medium alone was not significantly different from secretion in the wells exposed to M199 for $3 \mathrm{~h}$ that had been previously exposed to $24-\mathrm{h}$ dexamethasone $(n=5)$ (Fig. 5).

In another series of experiments, incubation of fetal pituitary cells with dexamethasone for $3 \mathrm{~h}$ did not induce significantly less secretion of ACTH than in control incubations. However, 3-h incubation of the cells with dexamethasone and CRF induced significantly lower ACTH secretion than that induced by 3-h exposure to CRF alone ( $n=5$ ) (Fig. 6). The effects of exposure to dexamethasone with CRF, AVP, or other secretagogues were completely reversed $24 \mathrm{~h}$ after removal of the steroid by multiple medium changes.

Interaction between CRF and catecholamines. The $\alpha$ - or $\beta$ adrenergic agonists, norepinephrine, or isoproterenol $\left(10^{-6} \mathrm{M}\right)$, did not result in significant change in ACTH secretion $(n=5)$. There was no change in ACTH secretion after a 3-h exposure to catecholamines alone or to a combination of catecholamines and CRF or AVP, compared with CRF or AVP alone $(n=5)$.

Interaction between $C R F$ and prostaglandin or indomethacin. Exposure of fetal pituitary cells to prostaglandin $\mathrm{E}_{1}\left(10^{-6} \mathrm{M} ; n\right.$ $=4)$ or to prostaglandin $\mathrm{E}_{2}\left(\mathrm{PGE}_{2}\right)\left(10^{-6} \mathrm{M} ; n=3\right)$ did not result in any significant change in ACTH secretion compared with that of control cells, either alone or in combination with CRF or AVP. Similarly, 3-h exposure to the prostaglandin synthetase inhibitor, indomethacin $(14 \mu \mathrm{M})$, did not elicit any significant change in ACTH secreted by the pituitary cells exposed to indomethacin alone or in combination with CRF or AVP, compared with control cells or cells exposed for $3 \mathrm{~h}$ to CRF or AVP.

\section{Discussion}

Synthetic hCRF can stimulate ACTH secretion by human fetal pituitary cells, at least as early as $14 \mathrm{wk}$ of fetal life. This is

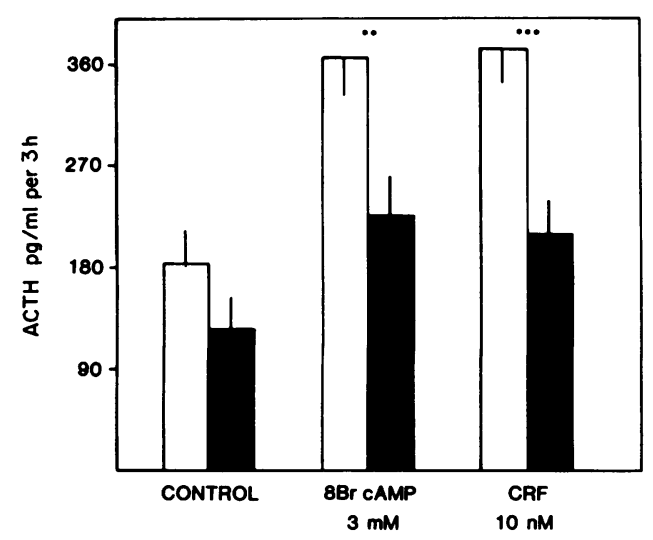

Figure 5. Mean ACTH secretion by dispersed human fetal pituitary cells exposed to CRF, 8-Br-cAMP, and control after 24-h incubation in the presence or absence of $20 \mathrm{nM}$ dexamethasone $(n=6) . \square$, M199; $n$, dexamethasone. Least square means \pm SEM. ${ }^{* * *} P<0.001$. $* * P$ $<0.01$.

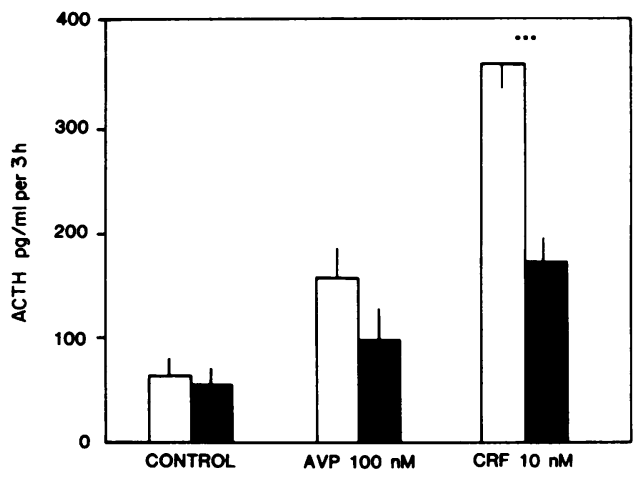

Figure 6. Mean ACTH secretion by dispersed human fetal pituitary cells after 3-h exposure to CRV, AVP, or medium in the presence and absence of 20 nM dexamethasone $(n=4)$. $\square$, M199; $\mathrm{a}$, dexamethasone. Least square means \pm SEM. ${ }^{* * *} P<0.001$.

consonant with our previous immunohistochemical demonstration of corticotropes in the human fetal pituitary by this stage of gestation (36). The reason for the inability of others to demonstrate fetal pituitary ACTH responsiveness until after 20 wk $(34,35)$ is not immediately apparent.

In human fetal pituitaries, as in rat adult pituitaries (27), AVP exhibits markedly lower potency than CRF in stimulating ACTH secretion; synergism was observed between CRF and physiologic concentrations of AVP.

Our study demonstrated that glucocorticoids can act directly on human fetal pituitary cells to blunt the ACTH response to CRF. Maximal inhibition of CRF-mediated ACTH secretion was observed in rat pituitaries after several hours of pretreatment with dexamethasone (27), as is typically seen with other transcriptionally mediated steroid effects. However, the acute inhibition of ACTH release, detected in human fetal pituitary cells as early as $3 \mathrm{~h}$ after incubation with dexamethasone and CRF, suggests that glucocorticoids may exert at least part of their negative feedback effects by affecting release of stored ACTH as well as transcription.

The similar effects of CRF and CAMP derivatives and the ACTH-releasing actions of agents known to elevate intracellular cAMP, such as phosphodiesterase inhibitors, cholera toxin, and forskolin, have suggested an involvement of the adenylate cyclase system in ACTH secretion $(23,27,51,52)$. CRF was found to rapidly elevate intracellular cAMP levels in rat anterior pituitary cell cultures, and glucocorticoid pretreatment markedly inhibited CRF-mediated increases in intracellular cAMP concentrations $(27,28)$. This was thought to indicate that the glucocorticoid effect might be mediated by altered cAMP levels. Our observation that glucocorticoids can inhibit ACTH secretion brought about by exogenous 8-Br-cAMP in human fetal pituitary cells suggests that glucocorticoids also act, in part, beyond the cAMP-generating step in their inhibition of CRF action.

The synergistic effects of AVP and CRF and of AVP and 8Br-cAMP, but not of CRF and 8-Br-cAMP, on ACTH secretion by human fetal pituitary cells are consonant with the hypothesis that there are different second messengers involved in the cellular actions of CRF and AVP (53). Whereas CRF action on ACTH release is mediated by the adenylate cyclase-protein kinase pathway, AVP action on ACTH release is modulated by a CAMPindependent mechanism that appears to be initiated by a rise in cytosolic calcium concentration (53).

Oxytocin was found to be an ACTH secretagogue and to act 
synergistically with CRF in rat pituitary cells in one study (27). However, others have described an antagonistic action of oxytocin on ACTH secretion when administered with AVP alone or with AVP and CRF in adult women (54). Plotsky (1) has found oxytocin concentrations in the range of $10^{-12} \mathrm{M}$ in systemic blood and $10^{-9} \mathrm{M}$ in the portal blood of adult rats. However, none of the concentrations of oxytocin used in our experiments $(0.2-20 \mathrm{nM})$ resulted in significant change in ACTH secretion by human fetal pituitary cells, either alone or in combination with CRF, AVP, or CRF + AVP. Thus, whether oxytocin has any physiologic role in $\mathrm{ACTH}$ regulation remains to be elucidated. It does not seem to play a major role in human fetal life, either as a secretagogue or as an inhibitor of ACTH secretion at the ages studied.

In contrast to their effects on adult animal pituitary cells (27), neither $\alpha$ - nor $\beta$-adrenergic agonistic catecholamines significantly modified ACTH secretion by human fetal pituitary cells under the study conditions employed.

Prostaglandins (PGs) are known to exist in the anterior pituitary gland, as are specific $\mathrm{PGE}_{2}$ binding sites (33). PGs are known to stimulate cAMP accumulation in anterior pituitary tissue $(53,55)$. Buckingham and Hodges $(56)$ found an increase in the release of ACTH from adenohypophyseal segments in vitro in response to $\mathrm{PGE}_{2}$, and others (57) reported a slight elevation of plasma corticosterone levels after injection of prostaglandin $E_{1}$ or prostaglandin $F_{1 \alpha}$ into the anterior pituitary of anesthetized, dexamethasone-pretreated rats. In contrast, no effects of prostaglandin $\mathrm{E}_{1}$ or $\mathrm{PGE}_{2}$ on basal ACTH release from rat anterior pituitary halves (58) or on basal ACTH and $\beta$-endorphin release from rat anterior pituitary cell cultures (59) were observed. $\mathrm{PGE}_{2}$ even inhibited $\mathrm{ACTH}$ production in anterior pituitary cell cultures after stimulation by a hypothalamic extract with CRF-like activity (59). More recently (33), $\mathrm{PGE}_{2}$ was found to be formed locally, after binding of the neurohormones, and to act as a negative feedback-modulator of vasopressin and CRF activity in the anterior pituitary gland. Our findings that PGs or indomethacin alone or in combination with CRF or AVP do not stimulate or inhibit ACTH secretion are similar to previous studies in rats (58). Although PGs may have a physiologic role in modulating ACTH secretion in the adult, this ability may not develop until late in intrauterine, or early in extrauterine, life.

We did not find a significant correlation between fetal age and the ACTH response to CRF or to CRF + AVP between 14 and 23 wk of human gestation, nor between the response of these second trimester human pituitary cells and the response of four rhesus term fetal pituitary cells. A correlation with age, however, has been found in sheep fetuses $(59,60)$ at a gestational age comparable to 28-34 wk in humans, a stage not amenable to testing in the human fetus.

The ontogenesis of the corticotrophs and their response to CRF, AVP, and glucocorticoids occurs before the 14th wk of fetal life. The response to catecholamines and prostaglandins may develop later in intra- or extrauterine life. In any case, the human fetal pituitary has the capacity to respond to stress stimuli in utero by the beginning of the second trimester of pregnancy. As previously reported $(1,2,8,15,16,21-26,32)$, the responses to stress stimuli consist mainly of regulation of ACTH secretion by CRF and AVP and feedback by adrenal glucocorticoids. Our studies in the human fetus demonstrate that the capacity for all of these responses exists at or before $14 \mathrm{wk}$ of intrauterine life.

A drawback of static incubation is the inability to assess precisely the time course of changes in hormonal secretion after exposure to a releasing factor or other modulator of secretion. The combination of superfusion and static incubation may be complimentary in understanding the complex interactions of various modulators of fetal pituitary hormone synthesis and secretion.

\section{Acknowledgments}

We are grateful to Dr. Robert Kuhn for his assistance with high performance liquid chromatography and Dr. Mary C. Martin for her invaluable help in obtaining specimens.

This work was supported in part by grant HD08478 from the National Institute of Child Health and Human Development.

Dr. Blumenfeld is a Postdoctoral Fellow in Reproductive Endocrinology and a recipient of an American Physician Fellowship.

\section{References}

1. Plotsky, P. M. 1985. Hypophysiotropic regulation of adenohypophyseal adrenocorticotropin secretion. Fed. Proc. 44:207-213.

2. Jones, M. T., B. Gillham, G. DiRenzo, U. Beckford, and M. C. Holmes. 1981. Neural control of corticotropin secretion. Front. Horm. Res. 8:12-43.

3. Rivier, J., and W. W. Vale. 1983. The organization of ovine corticotropin-releasing factor (CRF)-immunoreactive cells and fibers in the rat brain: an immunohistochemical study. Neuroendocrinology. 36:165186.

4. Zimmerman, E. A., G. Nilaver, A. Hou-You, and A. J. Silverman. 1984. Vasopressinergic and oxytocinergic pathways in the central nervous system. Fed. Proc. 43:91-96.

5. Buckingham, J. C., and J. R. Hodges. 1979. The secretion of corticotropin-releasing hormone in vitro: effects of neurotransmitter substances, drugs and corticosteroids. In Interactions Within the Brain-Pituitary-Adrenocortical System. M. T. Jones, B. Gillham, M. F. Dallman, S. Chattopadhyay, editors. Academic Press, London. 115-119.

6. Palkovits, M. 1977. Neural pathways involved in ACTH regulation. Ann. NY Acad. Sci. 297:455-476.

7. Vale, W., J. Spiess, J. Rivier, and C. Rivier. 1981. Characterization of a 41-residue ovine hypothalamic peptide that stimulates secretion of corticotropin and $\beta$-endorphin. Science (Wash. DC). 213:1394-1397.

8. Gillies, G. E., and P. J. Lowry. 1982. Corticotropin-releasing hormone and its vasopressin component. In Frontiers in Neuroendocrinology. W. F. Ganong and L. Martini, editors. Raven Press, New York. 7:45-75.

9. Giguere, V., and F. Labrie. 1983. Additive effects of epinephrine and corticotropin-releasing factor (CRF) on adrenocorticotropin release in rat anterior pituitary cells. Biochem. Biophys. Res. Commun. 110: 456-461.

10. Antoni, F. A., M. C. Holmes, and M. T. Jones. 1983. Oxytocin as well as vasopressin potentiates ovine CRF in vitro. Peptides (Fayetteville). 4:411-415.

11. Gibbs, D. M. 1984. High concentrations of oxytocin in hypophysial portal plasma. Endocrinology. 114:1216-1218.

12. Gibbs, D. M. 1985. Measurement of hypothalamic corticotropinreleasing factors in hypophyseal portal blood. Fed. Proc. 44:203-206.

13. Gibbs, D. M., and W. Vale. 1982. Presence of corticotropin releasing factor like immunoreactivity in hypophysial portal blood. Endocrinology. 111:1418-1420.

14. Johnston, C. A., D. M. Gibbs, and A. Negro-Vilar. 1983. High concentrations of epinephrine derived from a central source of 5-hydroxyindole-3-acetic acid in hypophysial portal plasma. Endocrinology. 113:819-821.

15. Plotsky, P. M., T. O. Bruhn, and W. Vale. 1985. Evidence for multifactor regulation of the adrenocorticotropin secretory response to hemodynamic stimuli. Endocrinology. 116:633. 
16. Plotsky, P. M., and W. Vale. 1984. Hemorrhage-induced secretion of corticotropin-releasing factor-like immunoreactivity into the rat hypophysial portal circulation and its inhibition by glucocorticoids. Endocrinology. 114:164-169.

17. Recht, L. D., D. L. Hoffman, J. Halder, A. J. Silverman, and E. A. Zimmerman. 1981. Vasopressin concentrations in hypophysial portal plasma: insignificant reduction following removal of the posterior pituitary gland. Neuroendocrinology. 33:88-90.

18. Wynn, P. C., G. Aquilera, J. Morell, and K. J. Catt. 1983. Properties and regulation of high-affinity pituitary receptors for corticotropinreleasing factor. Biochem. Biophys. Res. Commun. 110:602-608.

19. Van Leeuwen, F. W., and P. Wolters. 1983. Light microscopic autoradiographic localization of $\left({ }^{3} \mathrm{H}\right)$-arginine-vasopressin binding sites in the rat brain and kidney. Neurosci. Lett. 41:61-66.

20. Petrovic, S. L., J. K. McDonald, G. D. Snyder, and S. M. McCann. 1983. Characterization of $\beta$-adrenergic receptors in the rat brain and pituitary using a new high affinity ligand, $\left({ }^{125} \mathrm{I}\right)$ iodocyanopindolol. Brain Res. 262:249-253.

21. Yates, F. E., and J. W. Maran. 1974. Stimulation and inhibition of adrenocorticotropin release. Handb. Physiol. 4(Sect. 7):367.

22. Fleischer, N., and W. Vale. 1968. Inhibition of vasopressin-induced ACTH release from the pituitary by glucocorticoids in vitro. Endocrinology. 83:1232-1236.

23. Vale, W., and C. Rivier. 1977. Substances modulating the secretion of ACTH by cultured anterior pituitary cells. Fed. Proc. 36:20942099.

24. Kraicer, J., and J. Milligan. 1970. Suppression of ACTH release from adenohypophysis by corticosterone. Endocrinology. 87:371-376.

25. Sayers, G., and R. Portanova. 1974. Secretion of ACTH by isolated pituitary cells: kinetics of stimulation by CRF and inhibition by corticosterone. Endocrinology. 94:1723-1730.

26. Keller-Wood, M. E., and M. F. Dallman. 1984. Corticosteroid inhibition of ACTH secretion. Endocr. Rev. 5:1-18.

27. Vale, W., J. Vaughan, M. Smith, G. Yamamoto, J. Rivier, and C. Rivier. 1983. Effects of synthetic ovine corticotropin-releasing factor, catecholamines, neurohypophysial peptides, and other substances on cultured corticotropic cells. Endocrinology. 113:1121-1131.

28. Bilezikjian, L. M., and W. W. Vale. 1983. Glucocorticoids inhibit corticotropin-releasing factor-induced production of adenosine $3^{\prime}, 5^{\prime}$ monophosphate in cultured anterior pituitary cells. Endocrinology. 113: 657-662.

29. Giguere, V., J. Cote, and F. Labrie. 1981. Characteristics of the $\alpha$-adrenergic stimulation of adrenocorticotropin release by rat anterior pituitary cells. Endocrinology. 109:757-762.

30. Gillies, G., and P. Lowry. 1979. Corticotrophin releasing factor may be modulated by vasopressin. Nature (Lond.). 278:464-466.

31. Portanova, R., and G. Sayers. 1973. Isolated pituitary cells: CRF like activity of neurohypophysial and related polypeptides. Proc. Soc. Exp. Biol. Med. 143:661-666.

32. Buckingham, C. 1979. Corticotrophin releasing factor. Pharmacol. Rev. 31:253-275.

33. Vlaskovsak, M., G. Hertting, and W. Knepel. 1984. Adrenocorticotropin and $\beta$-endorphin release from rat adenohypophysis in vitro: inhibition by prostaglandin $E_{2}$ formed locally in response to vasopressin and corticotropin-releasing factor. Endocrinology. 115:895-903.

34. Gibbs, D. M., R. D. Stewart, J. H. Liu, W. Vale, J. Rivier, and S. S. C. Yen. 1982. Effects of synthetic corticotropin-releasing factor and dopamine on the release of immunoreactive $\beta$-endorphin/ $\beta$-lipotropin and $\alpha$-melanocyte-stimulating hormone from human fetal pituitaries in vitro. J. Clin. Endocrinol. Metab. 55:1149-1152.

35. Gibbs, D. M., R. D. Stewart, W. Vale, J. Rivier, and S. S. C. Yen. 1983. Synthetic corticotropin-releasing factor stimulates secretion of immunoreactive $\beta$-endorphin/ $\beta$-lipotropin and ACTH by human fetal pituitaries in vitro. Life Sci. 32:547-550.

36. Baker, B. L., and R. B. Jaffe. 1975. The genesis of cell types in the adenohypophysis of the human fetus as observed with immunocytochemistry. Am. J. Anat. 143:137-161.
37. Gyevai, A. T., L. V. Kuznetsova, E. Stark, B. Bukulya, and Z. Acs. 1982. In vitro study of functional maturation of CRF-ACTH axis in man, in the intrauterine period. Translated from Byull. Eksp. Biol. Med. 94:88.

38. Kraicer, J., and A. E. H. Chow. 1982. Release of growth hormone from purified somatotrophs: use of perifusion system to elucidate interrelations among $\mathrm{Ca}^{++}$, adenosine $3^{\prime}, 5^{\prime}$-monophosphate, and somatostatin. Endocrinology. 111:1173-1180.

39. O'Hare, M. J., and E. C. Nice. 1979. Hydrophobic high-performance liquid chromatography of hormonal polypeptides and proteins on alkylsilane-bonded silica. J. Chromatogr. 171:209-226.

40. Gospodarowicz, D., H. Bialecki, and G. Greenburg. 1978. Purification of the fibroblastic growth factor activity from bovine brain. $J$. Biol. Chem. 253:3736-3743.

41. Bethea, C. L., and R. I. Weiner. 1981. Human prolactin secreting adenoma cells maintained on extracellular matrix. Endocrinology. 108: 357-360.

42. Bethea, C. L., J. S. Ramsdell, R. B. Jaffe, C. B. Wilson, and R. I. Weiner. 1981. Characterization of dopaminergic regulation of human prolactin-secreting cells cultured on extracellular matrix. J. Clin. Endocrinol. Metab. 54:893-902.

43. Gospodarowicz, D., D. Cohen, and D. K. Fujii. 1982. Regulation of cell growth by the basal lamina and plasma factors: relevance to embryonic control of cell proliferation and differentiation. In Growth of Cells in Hormonally Defined Media. G. H. Sato, A. B. Pardee, and D. A. Sirbasku, editors. Cold Spring Harbor Laboratory, Cold Spring Harbor, New York. 95-214.

44. Barnes, D. W., M. Darman, and J. Orly. 1982. Serum-spreading factor: effects on RFI rat ovary cells and 1003 mouse embryonal carcinoma cells in serum-free medium. In Growth of Cells in Hormonally Defined Media. G. H. Sato, A. B. Pardee, and D. A. Sirbasku, editors. Cold Spring Harbor Laboratory, Cold Spring Harbor, New York. 155167.

45. Grotendorst, G. R., H. K. Kleinman, D. H. Rohrbach, A. T. Hewitt, H. H. Varner, E. A. Horigan, J. R. Hassell, V. P. Terranova, and G. R. Martin. 1982. Role of attachment factors in mediating the attachment, distribution and differentiation of cells. In Growth of Cells in Hormonally Defined Media. G. H. Sato, A. B. Pardee, and D. A. Sirbasku, editors. Cold Spring Harbor Laboratory, Cold Spring Harbor, New York. 403-413.

46. Gospodarowicz, D., A. L. Mescher, and C. R. Birdwell. 1977. Stimulation of corneal endothelial cell proliferation in vitro by fibroblast and epidermal growth factors. Exp. Eye Res. 25:75-89.

47. Rees, L. H., D. M. Cook, J. W. Kendall, C. F. Allen, R. M. Kramer, J. G. Ratcliffe, and R. A. Knight. 1971. A radioimmunoassay for rat plasma ACTH. Endocrinology. 89:254-261.

48. Hunter, W. M., and F. C. Greenwood. 1962. Preparation of Iodine-131 labelled human growth hormone of high specific activity. Nature (Lond.). 194:495-496.

49. Steel, R. G. D., and J. H. Torrie. 1960. Principles and Procedures of Statistics with Special Reference to the Biological Sciences. McGrawHill Book Co., New York.

50. Searle, S. R., F. M. Speed, and G. A. Milinken. 1980. Populations marginal means in the linear model. An alternative to least square means. Amer. Statist. 34:216-225.

51. Vale, W., C. Rivier, L. Yang, S. Minick, and R. Guillemin. 1978. Effects of purified hypothalamic corticotropin releasing factor and other substances on the secretion of adrenocorticotropin and $\beta$-endorphin-like immunoreactivities in vitro. Endocrinology. 103:1910-1917.

52. Fleischer, N., R. Donald, and R. Butcher. 1969. Involvement of adenosine 3'5'-monophosphate in release of ACTH. Am. J. Physiol. 217: $1287-1292$.

53. Aguilera, G., J. P. Harwood, J. X. Wilson, J. Morell, J. H. Brown, and K. J. Catt. 1983. Mechanisms of action of corticotropin-releasing factor and other regulators of corticotropin release in rat pituitary cells. J. Biol. Chem. 258:8039-8045.

54. Suh, S. Y., J. H. Liu, D. D. Rasmussen, D. M. Gibbs, and 
S. S. C. Yen. 1985. Oxytocin (OT) antagonizes the synergistic effect of vasopressin (VP) and ovine CRF (1-41)(OCRF) on ACTH release in normal cycling women. Paper presented at the 32nd annual meeting of the Society for Gynecologic Investigation. Phoenix, AZ. 235. (Abstr.)

55. Labrie, F., P. Borgeat, J. Drouin, L. Lagace, V. Giguere, V. Raymond, M. Godbout, J. Massicotte, L. Ferland, N. Barden, M. Beaulieu, J. Cote, J. Lepine, H. Meunier, and R. Veilleux. 1982. The role of cyclic nucleotides in the control of anterior pituitary gland activity. In Handbook of Experimental Pharmacology. J. W. Kebabian and J. A. Nathanson, editors. Springer-Verlag, Berlin. 58(II):525-566.

56. Buckingham, J. C., and J. R. Hodges. 1977. The use of corticotropin production by adenohypophysial tissue in vitro for the detection and estimation of potential corticotropin releasing factors. J. Endocrinol. 72:187-193.
57. Hedge, G. A., and S. D. Hanson. 1972. The effects of prostaglandins on ACTH secretion. Endocrinology. 91:925-933.

58. De Wied, D., A. Witter, D. H. G. Versteeg, and A. H. Mulder. 1969. Release of ACTH by substances of central nervous system origin. Endocrinology. 85:561-569.

59. Norman, L. J., S. J. Lye, and J. R. G. Challis. 1985. Changes in fetal ACTH responses to CRF during late gestation. Paper presented at the annual meeting of the Society for Gynecologic Investigation. Phoenix, AZ. 14. (Abstr.)

60. Rose, J. C., and B. Y. Hargrave. 1985. Developmental aspects of $\mathrm{ACTH}$ responses to corticotropin releasing factor (CRF) in lamb fetuses. Paper presented at the annual meeting of the Society for Gynecologic Investigation. Phoenix, AZ. 15. (Abstr.) 